\title{
Fire Performance of a Full-Scale Building Subjected to Earthquake Motions: Test Specimen, Seismic Motions and Performance of Fire Protection Systems
}

\author{
Jin-Kyung Kim ${ }^{1}$, Brian J. Meacham ${ }^{1}$, Haejun Park ${ }^{1,2}$, Tara Hutchinson ${ }^{3}$ and Elide Pantoli ${ }^{3}$ \\ ${ }^{1}$ Department of Fire Protection Engineering \\ Worcester Polytechnic Institute \\ 100 Institute Road, Worcester, MA 01609, USA \\ ${ }^{2}$ Olsson Fire \& Risk \\ 506 Hampton Street, Hampton, VIC 3188, Australia \\ ${ }^{3}$ Department of Structural Engineering \\ University of California, San Diego \\ 9500 Gilman Drive, La Jolla, CA 92093, USA
}

\begin{abstract}
A full-scale, five-story building specimen was erected on the Large Outdoor High Performance Shake Table (LHPOST) at the University of California, San Diego, outfitted with various nonstructural components and systems (NCSs), and subjected to a series of earthquake motion tests and compartment scale fire tests. The aim of these tests was to increase knowledge on the performance of NCS and contents during earthquakes and post-earthquake fire events. An overview of the building specimen, earthquake motions and performance of NCS critical to building fire safety are presented. Outcomes illustrate the extent of damage to compartment barriers, façade systems, egress systems and fire protection systems that could occur given different levels of ground motion, and how such damage could impact occupant life safety and emergency response during fires in earthquake-damaged buildings. Details of the postearthquake fire tests and fire performance observations are presented in an associated paper [1].
\end{abstract}

KEYWORDS: post-earthquake fire, structural response, compartmentation, and evacuation

\section{INTRODUCTION}

While developments in seismic analysis and design methods, building code provisions and mitigation technologies has significantly reduced the potential for structural collapse and associated loss of life as a result of earthquakes, damage to and losses associated with nonstructural components and systems (NCS) remains a concern. This is surprising given the loss potential associated with NCS. In the United States, it has been reported that the structural components of a commercial building account for approximately 15$25 \%$ of the original construction cost, while the nonstructural (mechanical, electrical, plumbing, and architectural) components account for the remaining $75-85 \%$ of the cost [2]. Significant NCS-associated losses have occurred due to earthquakes. In the 1994 Northridge earthquake, NCS damage was reported to have accounted for $50 \%$ of the $\$ 18.5$ billion loss associated with building damage [3]. Similarly, NCS damage was reported to account for the majority of the total losses in the 2010 Maule earthquake in Chile [4]. In addition to losses associated with earthquakes alone, the performance of NCS are also important in terms of post-earthquake fire performance, since all active and most passive fire protection systems are considered NCS. The impact of damage to fire protection NCS has been observed in numerous earthquakes, including the 1994 Northridge and 1995 Kobe earthquakes, where damage to fire sprinkler systems and fire doors was reported to be over $40 \%$ and $30 \%$ respectively [5]. While building codes and standards have addressed seismic performance of some fire protection systems as a result of these events, such as improved requirements for sprinkler hangars and bracing, there has not been much focus on other areas, such as seismic performance of compartment barriers, doors and stairways, which form important parts of egress systems. The implications of such omissions have also been observed in earthquake events. In the 2010 and 2011 Christchurch earthquakes, for example, interior stairs collapsed and impeded safe evacuation [6]. Such failures not only impact the ability of occupants to escape, but impact the ability of first responders to enter buildings and conduct rescue and firefighting operations. As evident from these events and others, damage to fire protection NCS can result in occupants and first responders being placed 
at risk in case of post-earthquake fires. Data such as these clearly show that more work is needed to improve the seismic performance of NCS: not only those which can result in high direct and indirect monetary losses, but those which can impact safety to occupants and first responders [7].

To better understand, characterize and predict the potential damage to NCS during earthquakes and postearthquake fires, a full-scale five-story building specimen was constructed, equipped with various NCS and contents, and subjected to a series of earthquake motion tests and post-earthquake fire tests. Referred to as the BNCS Project, this unique collaboration between academia, government, and industry was developed with the aim to expand on the knowledge of the performance of the NCS during earthquakes and postearthquake fires [8]. Details on the program and partners can be found at the project website (http://bncs.ucsd.edu/index.html). The test facility, building specimen, earthquake motions and earthquake performance of the fire protection NCS are described below. The fire test program and results are presented in a corresponding paper [1]. Full documentation of the test program, preliminary data and summaries of the test program and preliminary data are available [8-13].

\section{EXPERIMENTAL FACILITIES}

Experiments were performed on the large high performance outdoor shake table (LHPOST) at the Englekirk Structural Engineering Center of the University of California, San Diego. The LHPOST, shown in Fig. 1, measures $7.6 \mathrm{~m}$ by $12.2 \mathrm{~m}$ and is able to reach a peak acceleration of $4.2 \mathrm{~g}$ and a peak velocity of $1.8 \mathrm{~m} / \mathrm{s}$ (unloaded) in the East/West direction. Addition details can be found at (http://nees.ucsd.edlu).

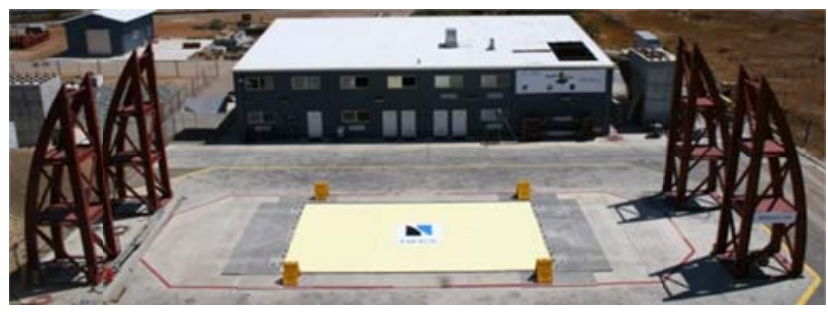

Fig. 1. LHPOST at the test site.

\section{BUILDING DESIGN}

The building specimen was designed with the assumption that it was to be located in a high seismic zone in Southern California (Site Class D [14]). Spectrally matched and chosen from seven maximum considered earthquake (MCE) ground motions and three serviceability motions, the design targeted an inter-story drift ratio (IDR) of $2.5 \%$ and maximum peak floor acceleration (PFA) of $0.7 \mathrm{~g}$ to $0.8 \mathrm{~g}$ [8]. IDR and PFA are commonly used earthquake demand parameters, where IDR is defined as the relative story displacement divided by the story height and PFA is defined as the maximum absolute floor acceleration.

\section{Building Specimen}

The building specimen was constructed of poured-in-place concrete and had plan dimensions of $6.6 \mathrm{~m}$ by $11 \mathrm{~m}$ with floor-to-floor heights of $4.27 \mathrm{~m}$ at all levels. A $0.2 \mathrm{~m}$ thick concrete slab was placed at each level, with two large openings of $2.1 \mathrm{~m}$ by $2.6 \mathrm{~m}$ and $2.3 \mathrm{~m}$ by $4.2 \mathrm{~m}$ at all floors to accommodate an operable elevator and complete stair assembly, respectively. At the back and sides of the elevator shaft area, small penetration openings for various building services such as plumbing and automatic fire sprinklers were provided. A $15 \mathrm{~cm}$ thick concrete wall was constructed on both the east and west sides of the elevator opening to provide support for the elevator guardrails. Seismic resistance for the building was provided by special one-bay moment resisting frames in the Northeast and Southeast bays. Moment resisting beams at each floor were designed with the same capacities but with varying components as shown in Fig. 2b. Each of the six $66 \mathrm{~cm}$ by $46 \mathrm{~cm}$ rectangular columns were reinforced with longitudinal bars and a prefabricated transverse reinforcement grid. Details of the structural system are provided in [8, 9]. 


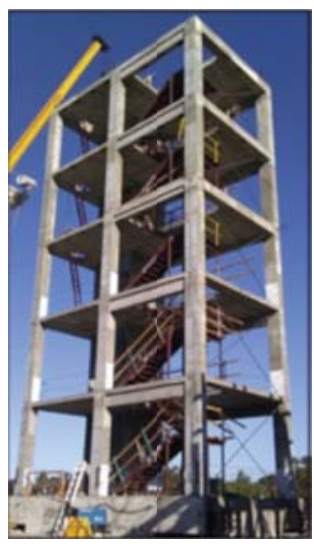

(a)

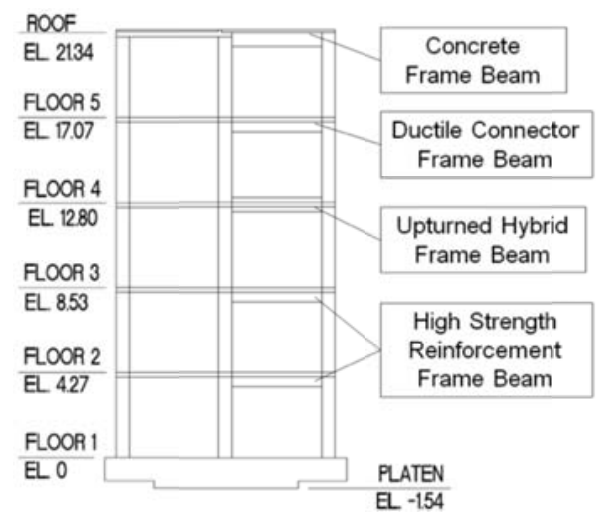

(b)

Fig. 2. Test specimen (a) skeleton; (b) elevation view (elevation in m) [images and schematic from 8].

\section{Architectural Components}

The building specimen was outfitted with a number of architectural components to reflect a typical multistory building. This included enclosed interior stairway, compartments framed with lightweight steel studs and covered by gypsum board panels, doorways with swinging doors, and a variety of ceiling systems. Such architectural components are important for fire safety analysis as they provide full loading for the fire and also provide compartments to resist the spread of smoke and flame as well as required egress system components. The building frame was enclosed using two architectural façade systems. The first three floors were enclosed by a balloon framing system comprised of lightweight steel studs, gypsum board interior faces and an exterior insulation and finishing system (EIFS) as shown in Fig. 3a. On Floors 4-5, precast concrete cladding panels were used [8]. Each façade system included window openings but no glazing system. The interior gypsum board on the balloon frame façade was $1.6 \mathrm{~cm}$, fire-rated, Type X. Ceiling systems were installed in the Northeast and Southeast portions of each floor of the specimen. Different ceiling were installed on each floor. Details on the various ceiling systems can be found in project publication [8]. The ceiling system of Floor 3, focus of fire testing, was a gypsum board grid system (Fig. $3 b)$. Interior partition walls were installed on all floors of the building specimen. Partition walls on Floor 3 featured two layers of $1.6 \mathrm{~cm}$ (5/8 in) Type-X gypsum board on steel studs as shown in Fig. 3c [8]. The elevator shaft was enclosed using a layer of $1.6 \mathrm{~cm}$ (5/8 in) Type X, fire rated gypsum board on each side of the walls. The elevator lobby on Floor 3 was enclosed using one layer of $1.6 \mathrm{~cm}(5 / 8$ in) Type X, fire rated gypsum board. The stairwell was partially enclosed by one layer of $1.6 \mathrm{~cm}$ (5/8 in) gypsum bioard.

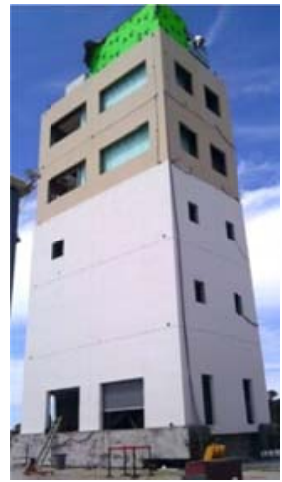

(a)

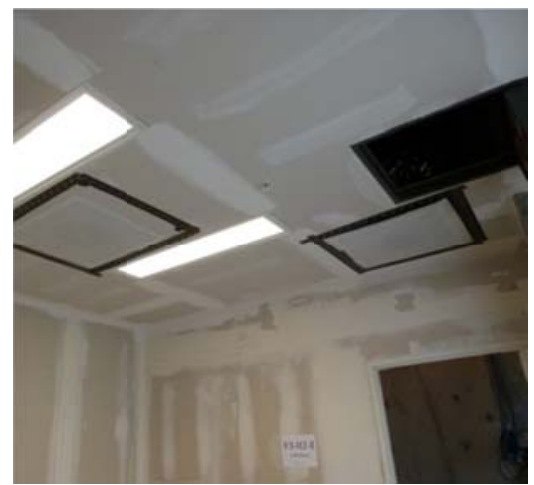

(b)

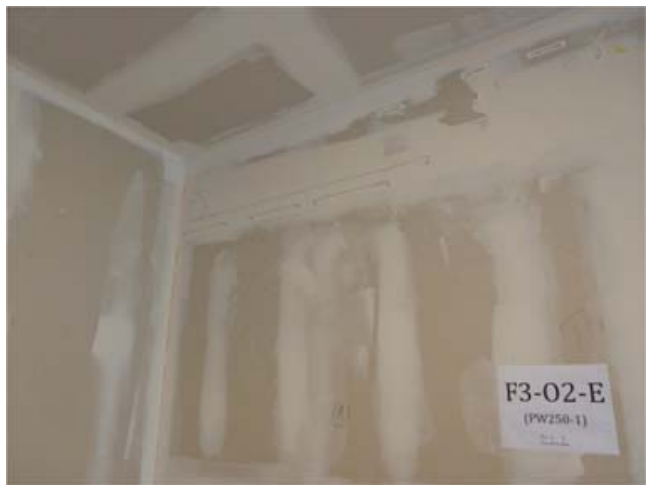

(c)

Fig. 3. (a) Façades systems; (b) Floor 3 ceiling system (c) Floor 3 partitions.

The focus for assessment of fire performance of NCS was Floor 3, as live fire testing was limited to this floor (however, data on other floors was also collected). The architectural layout for Floor 3 is shown in Fig. 4. Floor 3 was separated into four different compartments and designated as the Large Burn Room (LBR), Small Burn Room (SBR), area behind the Elevator Shaft (ES) and the Elevator Lobby (EL). The 
LBR and SBR were separated by a partition wall that extended up to the ceiling height. Ceiling systems were installed in the LBR, SBR and EL spaces. Window openings were provided in all compartments but no glazing system was installed in any of the openings. While the focus was on Floor 3 NCS performance for fire, data and observations from other systems on other floors were also recorded.

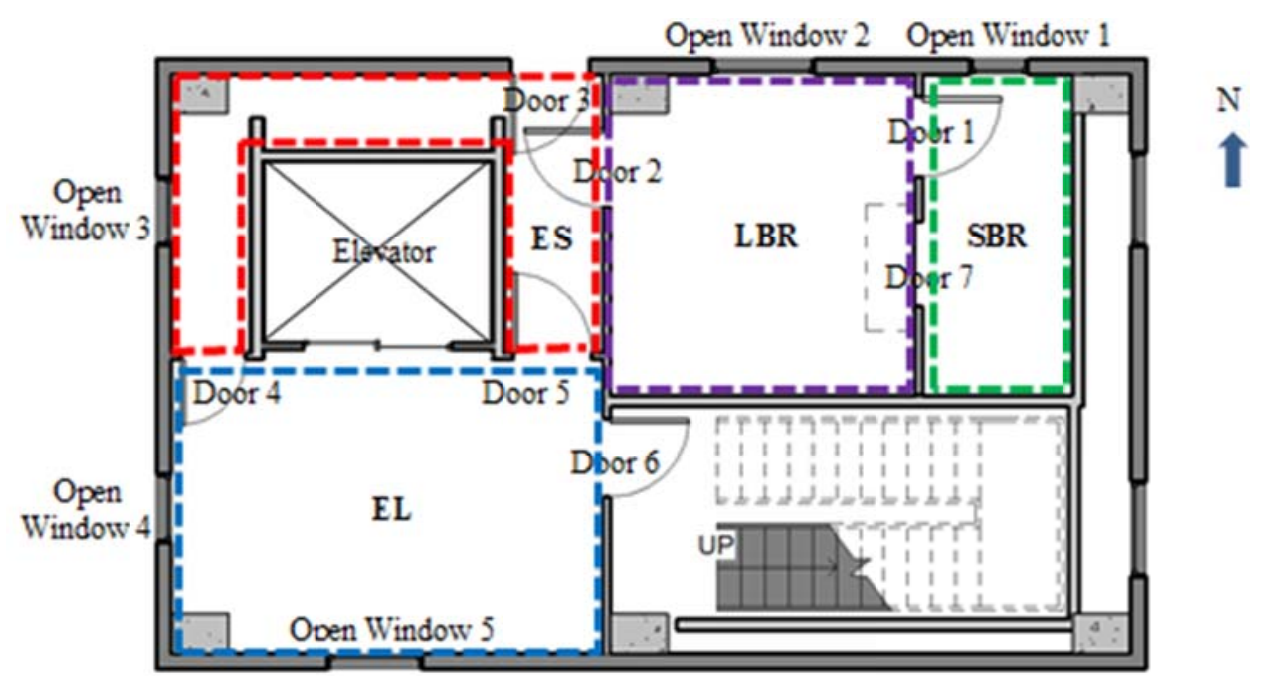

Fig. 4. Floor plan of Floor 3

Fire Protection and Mechanical Systems

A functional wet pipe automatic sprinkler system was installed throughout the building specimen. Risers $\left(6.35 \mathrm{~cm}\left(2 \frac{1}{2} \mathrm{in}\right)\right)$ and control valves were installed on the West elevator shaft wall at each floor level. Branch and loop line pipe material and layout varied by floor. The details of the sprinkler system components are listed in Table 1. All horizontal sprinkler branch and loop lines were installed $30 \mathrm{~cm}$ (12 in) below the deck of the floor above.

Table 1. Sprinkler system components

\begin{tabular}{|c|c|c|}
\hline Level & Pipe & $\begin{array}{c}\text { Sprinkler Head } \\
\end{array}$ \\
\hline Floor 1 & $\begin{array}{l}3.8 \mathrm{~cm} \text { (1 1/2 in) Steel Schedule } 10 \text { main line } \\
2.5 \mathrm{~cm} \text { (1 in) Steel Schedule } 40 \text { branch line }\end{array}$ & $\begin{array}{l}4 \text { Quick Response Pendent } \\
3 \text { Quick Response Upright }\end{array}$ \\
\hline Floor 2 & $\begin{array}{l}3.8 \mathrm{~cm}(1 \mathrm{1} / 2 \mathrm{in}) \mathrm{CPVC} \text { main line } \\
2.5 \mathrm{~cm}(1 \mathrm{in}) \mathrm{CPVC} \text { branch line }\end{array}$ & $\begin{array}{l}2 \text { Quick Response Pendent } \\
2 \text { Quick Response Upright } \\
2 \text { Residential Concealed Pendent }\end{array}$ \\
\hline Floor 3 & $\begin{array}{l}3.8 \mathrm{~cm} \text { (1 1/2 in) Steel Schedule } 10 \text { main line } \\
2.5 \mathrm{~cm} \text { ( } 1 \text { in) Steel Schedule } 40 \text { branch line }\end{array}$ & $\begin{array}{l}4 \text { Quick Response Pendent } \\
3 \text { Quick Response Upright }\end{array}$ \\
\hline Floor 4 & $\begin{array}{l}3.8 \mathrm{~cm}\left(1 \frac{1}{2} \text { in) Steel Schedule } 10 \text { main line }\right. \\
2.5 \mathrm{~cm} \text { ( } 1 \text { in) Steel Schedule } 40 \text { branch line }\end{array}$ & $\begin{array}{l}3 \text { Quick Response Pendent } \\
3 \text { Quick Response Upright }\end{array}$ \\
\hline Floor 5 & $\begin{array}{l}3.8 \mathrm{~cm}(1 \mathrm{1} / 2 \text { in) Steel Schedule } 10 \text { main line } \\
2.5 \mathrm{~cm} \text { ( } 1 \text { in) Steel Schedule } 40 \text { branch line }\end{array}$ & $\begin{array}{l}4 \text { Quick Response Pendent } \\
3 \text { Quick Response Upright }\end{array}$ \\
\hline
\end{tabular}

Differences in pipe material and layout were used to assess performance of the various configurations under seismic load. Hangers and bracing were provided to comply with current building code requirements. On Floors 1 and 4, sand weights were attached on branch / loop lines to represent pipes with larger diameters to assess seismic performance given increased loads. Representative sprinkler system layouts are shown in Fig. 5. The figures reflect U.S. units, as presented in [10]. Additional detail on the sprinkler system design, including calculations, components and layout, can be found in [10]. To obtain realistic seismic performance, while minimizing any possible water damage to equipment for potential pipe rupture, the system was charged with only 57 liters (15 gallons) of water at each floor during motion tests. 


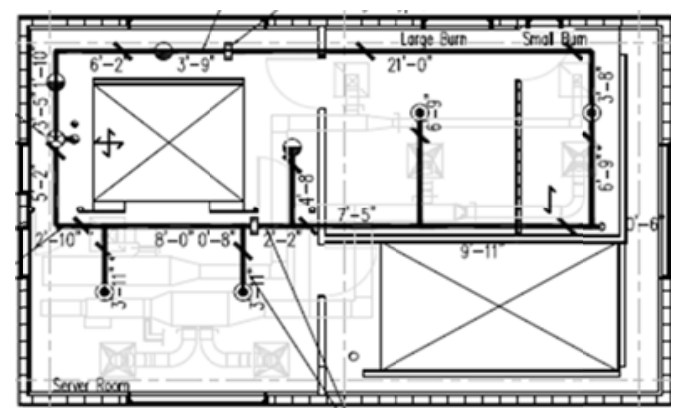

(a)

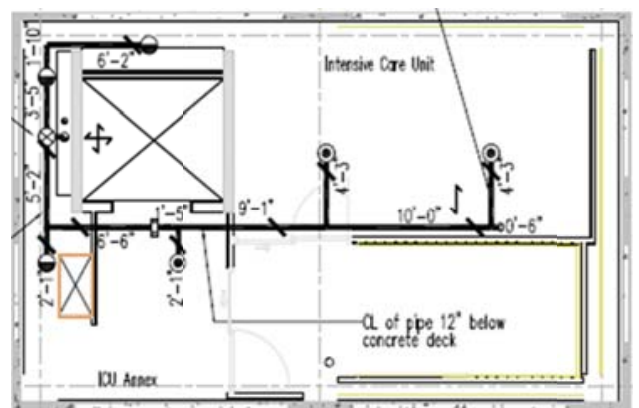

(b)

Fig. 5. Sprinkler system layout for (a) Floor 3 and (b) Floor 4 [10].

Heating, ventilation air-conditioning (HVAC) ductwork was installed on Floor 3 and vented to the outside through a vertical duct on Floor 4. Ductwork was comprised of sheet metal. Flexible duct connections were installed between ducts and diffusers located in the Floor 3 ceiling. The supply and return ducts were located in the plenum spaces. Fire and smoke dampers were located in the ductwork portions in the ES and the stair landing area. This is shown in Fig. 6.

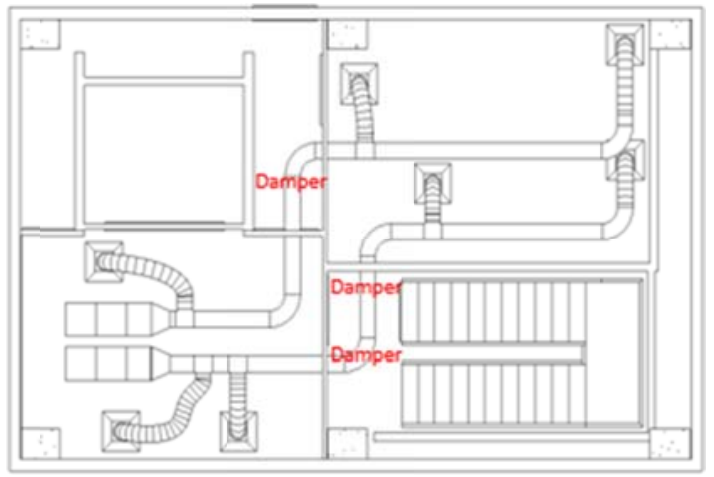

Fig. 6. Location of fire and smoke dampers

The duct connections were firestopped with fire caulk. Spaces around the ducts, where they penetrated interior partitions, were sealed with fire stop material. HVAC ducts in the corridor around the elevator shaft and within the stairway landing were exposed (no ceiling systems). A portion of the actual HVAC system is shown in Fig. 7b. The HVAC and other mechanical systems are described in more detail in [8].

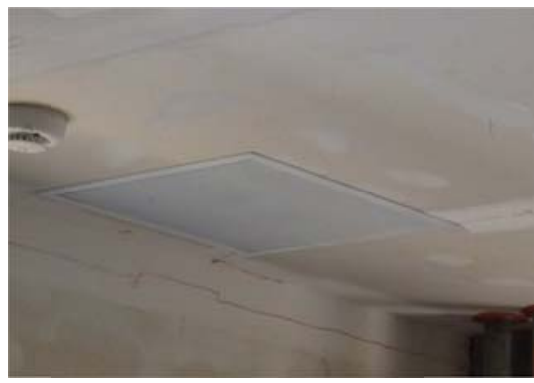

(a)

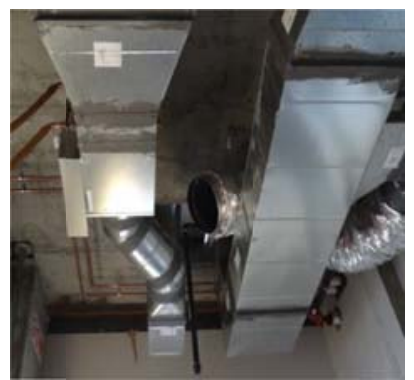

(b)

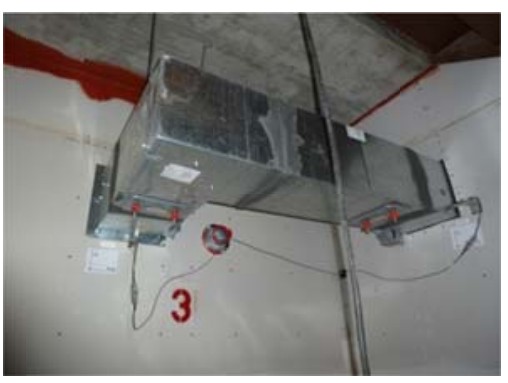

(c)

Fig. 7. (a) Diffuser in ceiling; (b) HVAC ductwork; (c) fire-stopping around duct [figure 7b from 8]

\section{Egress Systems}

A prefabricated stair assembly was installed at each floor of the building as shown in Fig. 8a. Each floor consisted of lower and upper flights and an intermediate landing. The stair flights were connected with the concrete floor slabs at one end via field welds, while they were connected with a stair landing via bolts at the other end. A fully functioning elevator with $17.1 \mathrm{~m}$ travel height and access to all floors was installed in a $2.64 \mathrm{~m}$ by $2.1 \mathrm{~m}$ elevator shaft as shown in Fig. 8b-c. During the seismic tests, the $1.92 \mathrm{~m}$ by $1.7 \mathrm{~m}$ by 
$2.36 \mathrm{~m}$ cab was loaded with sand bags equivalent to $40 \%$ of the full cab capacity of $160 \mathrm{~kg}$ [8]. The opening of the cab door was $2.1 \mathrm{~m}$ by $1.1 \mathrm{~m}$ as shown in Fig. 8c.

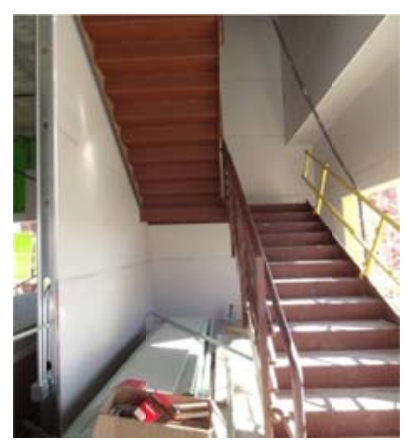

(a)

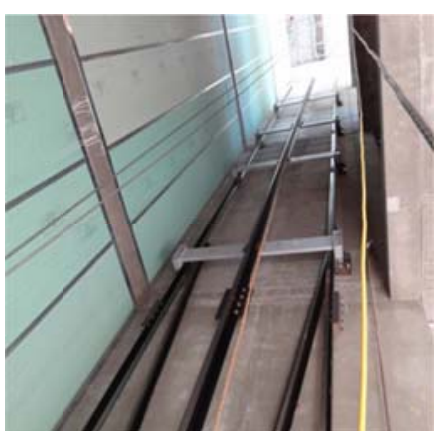

(b)

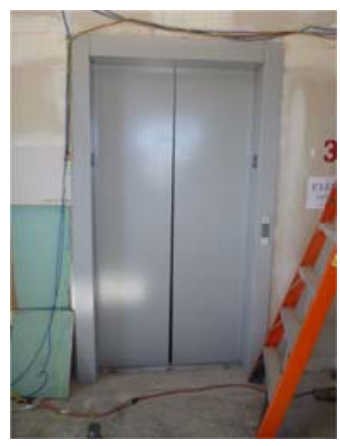

(c)

Fig. 8. Egress systems (a) stair; (b) elevator guiderails; (c) elevator door. [images 8a and 8b from 8]

\section{Additional Fire Protection Features}

In addition to a sprinkler system and fire dampers in the HVAC ductwork as overviewed above, various other fire protection features were installed on Floor 3, which was designated for later live fire tesits. A 1-hr fire resistance rated roll-down steel fire door was installed in the middle of the partition wall separating the LBR and SBR (see Fig. 4). Door closers and magnetic door holders were installed for all interior doors, which were 20-minute fire resistance rated. As noted above, compartments walls were comprised of two layers of Type X gypsum, with exterior walls including window openings without glazing systemı. Smoke detectors were located at various locations and programmed into the fire alarm control panel system. Firestop sealants and devices were installed in all vertical and horizontal pipe, cable, wire and HVAC penetration openings on the third floor. Various firestop components of intumescent, non-intumesscent and mineral fiber wool were applied, as dictated by previously fire-tested and listed firestop designs from the Underwriters Laboratories (UL) Fire Resistance Directory. The fire door, door closers and magnetic door holders, and firestop systems are shown in Fig. 9 [10].

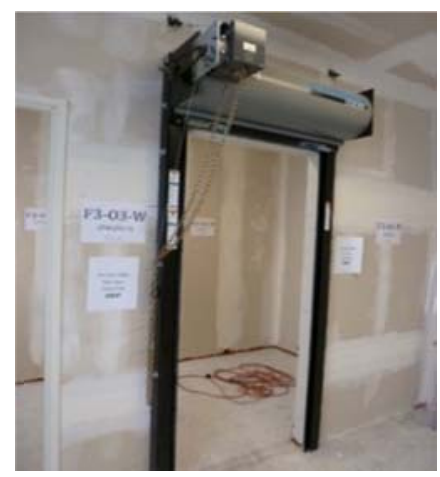

(a)

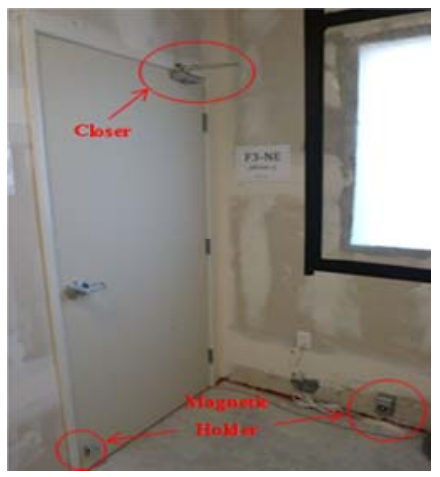

(b)

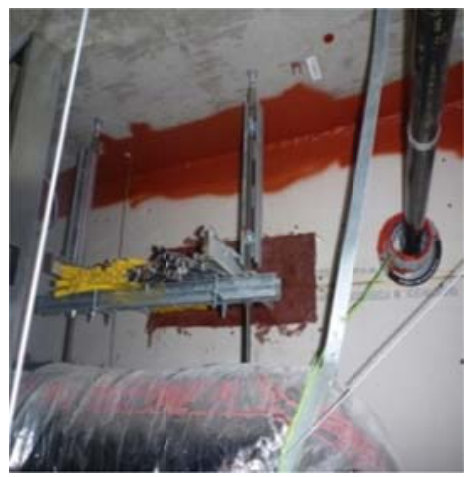

(c)

Fig. 9. Fire protection systems on Floor 3 (a) fire door; (b) door closer and holder (c) fire stop systems.

\section{Occupancies and Contents}

The building specimen was designed to have spaces reflective of different building occupancies, including hospital surgery suite (Floor 5), intensive care unit (ICU) (Floor 4), computer servers (Floor 3), residential and laboratory content (Floor 2) and building services (Roof and Floor 1). Specific floors were: outfitted with additional architectural features based on occupancy and test objectives, including ICU smoke doors (Floors 4 and 5) and a roll-down fire door on Floor 3 (level of fire testing). The occupancy characteristics are summarized in Table 2 and representative photos are shown in Fig. 10. 
Table 2. Occupancy characteristics

\begin{tabular}{|c|c|l|c|c|l|}
\hline Floor & Figure & Occupancy & Floor & Figure & Occupancy \\
\hline 1 & $10 \mathrm{a}$ & Utilities & 4 & $10 \mathrm{~d}$ & Medical equipment: ICU \\
\hline 2 & $10 \mathrm{~b}$ & Residential and laboratory content & 5 & $10 \mathrm{e}$ & Medical equipment: surgery suite \\
\hline 3 & $10 \mathrm{c}$ & Computer servers & Roof & $10 \mathrm{f}$ & Roof mounted equipment \\
\hline
\end{tabular}

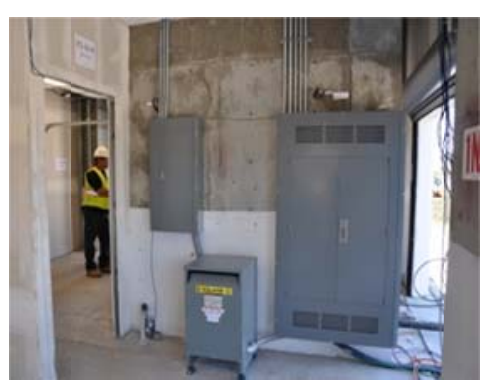

(a)

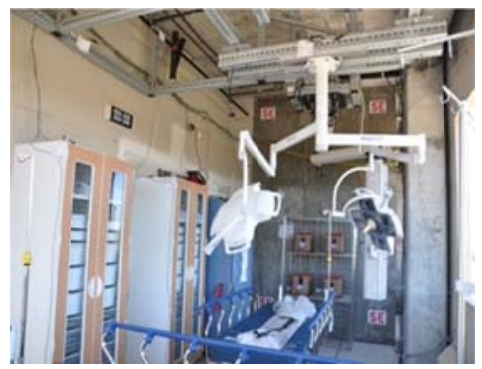

(d)

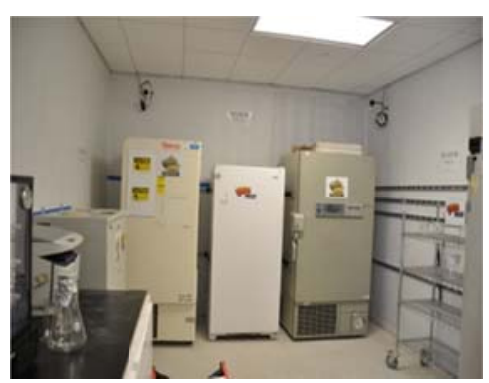

(b)

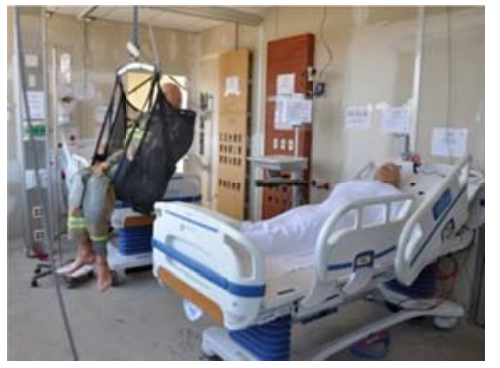

(e)

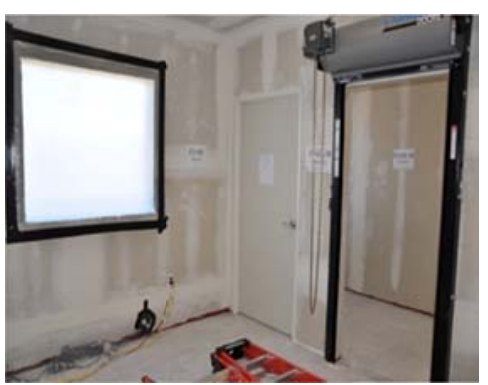

(c)

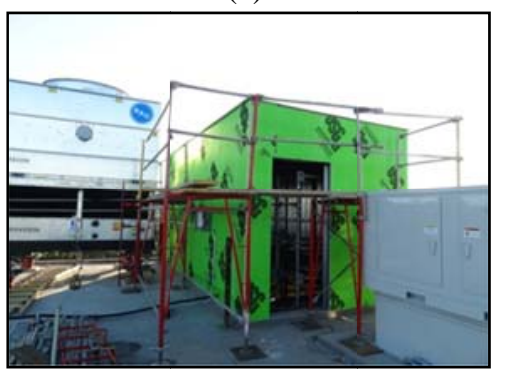

(f)

Fig. 10. Photos of the various floors of the building - refer to Table 2 [images from 8]

\section{EARTHQUAKE MOTION TESTS}

Earthquake motion tests consisted of 13 tests conducted in 2 configurations, namely while the buillding was base-isolated (BI) and fixed base (FB). Seven tests were conducted while the building was BI and six while it was FB. Four high damping rubber isolators were installed at the four corners of the building for the BI tests and subsequently removed for the FB tests. The seismic motions for the BI configuration and FB configuration are shown in Table 3.

Table 3. Input ground motions.

\begin{tabular}{|l|l|l||}
\hline \multicolumn{1}{|c|}{ Date } & \multicolumn{1}{|c|}{ Name } & \multicolumn{1}{c|}{ Seed Motion } \\
\hline \multirow{2}{*}{ April 16, 2012 } & BI-1: CNP 100 & Canoga Park 1994 Northridge Earthquake \\
\cline { 2 - 3 } & BI-2: LAC 100 & LA City Terrace 1994 Northridge Earthquake \\
\hline \multirow{2}{*}{ April 17, 2012} & BI-3: LAC 100 & LA City Terrace 1994 Northridge Earthquake \\
\cline { 2 - 3 } & BI-4: SP 100 & San Pedro 2010 Maule (Chile) Earthquake \\
\hline April 26, 2012 & BI-5: ICA 50 & 2007 Pisco (Peru) Earthquake \\
\hline \multirow{2}{*}{ April 27, 2012 } & BI-6: ICA 100 & 2007 Pisco (Peru) Earthquake \\
\cline { 2 - 3 } & BI-7: ICA 140 & 2007 Pisco (Peru) Earthquake \\
\hline May 7, 2012 & FB-1: CNP 100 & Canoga Park 1994 Northridge Earthquake \\
\hline \multirow{2}{*}{ May 9, 2012 } & FB-2: LAC 100 & LA City Terrace 1994 Northridge Earthquake \\
\cline { 2 - 3 } & FB-3: ICA 50 & 2007 Pisco (Peru) Earthquake \\
\hline May 11, 2012 & FB-4: ICA 100 & 2007 Pisco (Peru) Earthquake \\
\hline \multirow{2}{*}{ May 15, 2012 } & FB-5: DEN 67 & Pump Station \#9 2002 Denali Earthquake \\
\cline { 2 - 3 } & FB-6: DEN 100 & Pump Station \#9 2002 Denali Earthquake \\
\hline
\end{tabular}

Motions were selected from earthquake events occurring off the coast of California, in the central area of Alaska and the subduction zone of South America and applied in a progressive manner to increase the seismic demand on the test specimen. To compare the response and behavior of the structure and NCSs, the early (target) motions in the sequence of the BI and FB testing phases were intended to be similar. In 
addition a long duration motion from the 2007 Peru earthquake was selected and amplitude scaled (50, 100, and $140 \%$, the later applied only during the BI testing phase). It was desirable to minimize the peak interstory drift ratio (PIDR) to less than approximately $0.5 \%$ while the test specimen was isolated at its base, to preserve the structure for the FB testing phase. The design event imposed during the FB testing phase was intended to achieve the performance target of about 2.5\% PIDR and $0.8 \mathrm{~g}$ peak floor acceleration selected initially in the specimen design. The achieved peak input acceleration range for the FB earthquake motions ranged from about 0.2 to $0.8 \mathrm{~g}$, while the pseudo-spectral acceleration at a period of 1 second (the target fundamental period of the building) ranged from about 0.3 to 1.3 g. Motion FB-5 imposed inter story drifts associated with the design performance target of about 2.8\% PIDR for the building specimen, while the final motion FB-6 damaged the building specimen severely, and compromised its lateral resisting structural system, resulting in very large PIDR of approximately 6\% - a value well outside of anticipated design code performance targets under design earthquakes [9]. The motions are detailed in [8, 9, 11, 12].

\section{FIRE SAFETY SYSTEMS PERFORMANCE}

The earthquake motions induced damage to compartment barrier components, façade and egressi systems, caused displacement of heavy contents, exposed steel reinforcing bars, and disconnected pipes. Regarding compartment integrity, gaps were formed in joint areas and ceiling tiles were displaced, while door components were damaged, providing potential means of smoke and flame spread. Egress component damage included disconnected stairs and elevator door failure. Corridors became obstructed with displaced items which could possibly hinder occupants from safely evacuating. Concrete spalling rendered steel reinforcing bars exposed, which could degrade fire resistance of structural reinforced concrete. All of the active fire protection systems remained undamaged and intact throughout the motion tests. Several of these issues are discussed in more detail below.

\section{Contents / Fuel Distribution}

Fire intensity and duration can be affected by the amount, distribution, shape, arrangement and moisture of fuel loads. Fuel distribution and arrangement can be greatly altered due to earthquakes since contents can be displaced from their original location, in some cases bringing fuels close together, which could facilitate fire spread. The displacement of items during earthquakes can also cause a reduction in occupant walking speed and impact evacuation behavior. Research by Hokugo et al. [15] revealed that the total evacuation time was longer with obstructed pathways than without, becoming longer as the size of obstructions increase and the effective egress width and travel speed decrease.

A range of contents reflective of the occupancies on Floors 2, 4 and 5 were located in the specimen. Some contents were anchored while others were not. Displacement of unsecured contents (potential fuel items) was experienced on each floor during motion tests, with the extent of displacement increasing with the size of the simulated events (see [11] for details on motions, contents and anchorage, and resulting acceleration, drift and displacement). As an example, Floor 2 included chemical laboratory and storage equipment in one space and living room contents in another. Only minor displacement of the smaller items such as cups and dishes on the dining table were observed during all the seismic motion tests leading up to FB-4. Following the largest seismic motion tests of FB-5 and FB-6, not only did small items such as cups and dishes get displaced and shattered but also large items such as a fully loaded bookshelf and anchored TV were displaced. The glass beakers and testing tubes fell off the workstations and shattered on the ground. Pictures of the Floor 2 areas with displaced contents following FB-6 are shown in Fig. 11.

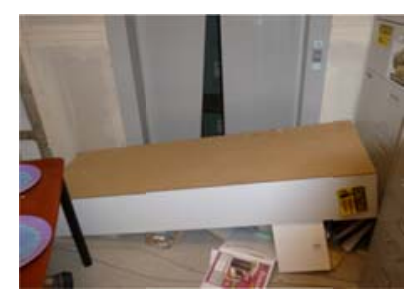

(a)

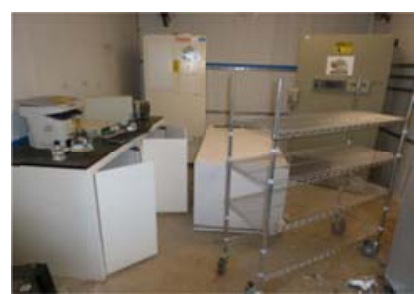

(b)

Fig. 11. Displaced items on Floor 2 following FB-6 (a) living room space (note large gap in elevator door in background) (b) chemical lab and storage space. 


\section{Means of Egress Issues}

Egress systems require continuous and unobstructed paths, either vertical or horizontal, that allows occupants not intimate with the initial incident such as a fire, to escape or reach a place of safety from the hazard before being exposed to untenable conditions. Damage to the egress systems components due to earthquakes is a concern since it could hinder occupant evacuation and the fire service operations. As a result of the FB-5 and FB-6 motion tests, damage to multiple egress components was observed. Interior door frames became distorted and some door latches were damaged. These conditions either prevented doors from closing completely or made doors difficult to open. In one case the strength of the magnetic door holder exceeded the strength of the connection of the strike plate, resulting in the strike plate being ripped off the door. In another case a door was completely jammed and shut and required tools to pry the door open [10]. Stairs became detached from the concrete floor slab and handrails fractured at a number of locations. Fig. 12 reflects damage levels of the stairs at all floors during FB-5 and FB-6. The minor damage level means no repair required, the moderate damage level means repair required, and the severe damage level means immediate repair required to assure safe operability of the stairs [13]. At various locations throughout the egress system gypsum wallboards were detached from the walls, including exit access (e.g., within compartments and elevator lobby) and exits (stairways), as well as on shaft enclosures. More complete discussion of egress system component damage after all motions can be found in [10, 13, 14]

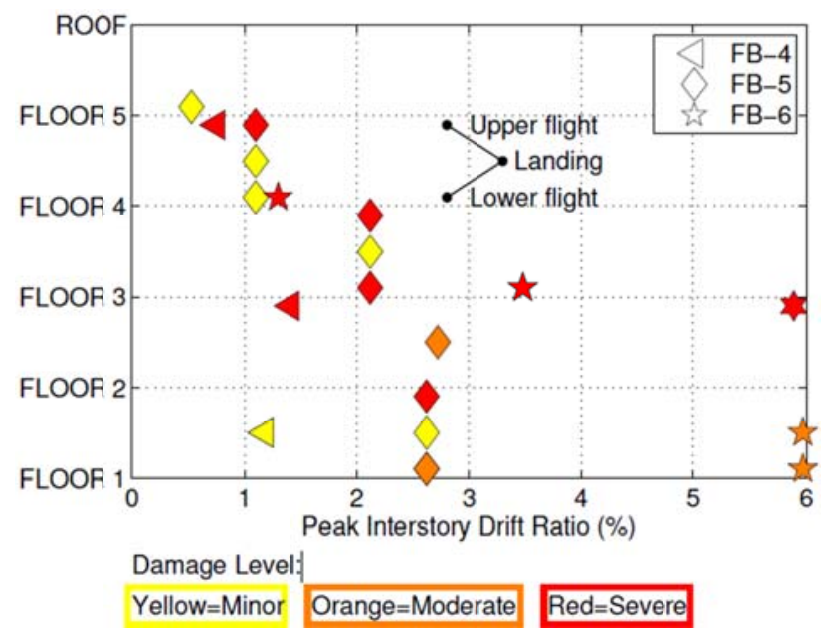

Fig. 12. Summary of damage to the stairs [figure from 13].

While not a component of all means of egress, the use of elevators for occupant evacuation is increasing in tall buildings. As such, its performance is of particular concern for high-rise buildings. During these tests, the elevator system performed quite well, remaining functional until the FB-5 motion despite minor gapping at the elevator doors. Following the FB-6 motion, although there was minimal damage to the mechanical components and rail subsystem of the elevator, the elevator was inoperable as the elevator doors experienced severe distortion at floors one to three. The various damage conditions outlined above are illustrated in Fig. 13, including damage to the elevator door (Fig. 13a), stairs detachment from the concrete floor slab (Fig. 13b) and loss of gypsum wallboard within the stair at Floor 3 (Fig. 13c).

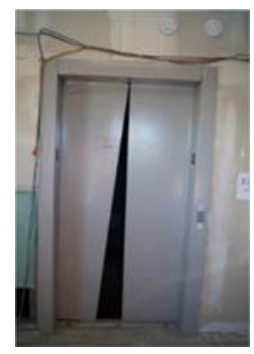

(a)

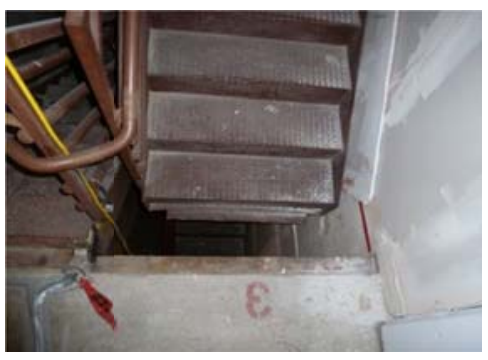

(b)

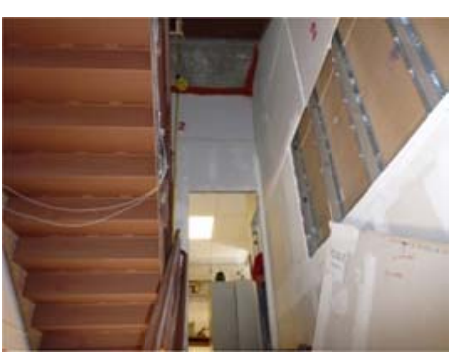

(c)

Fig. 13. Damage to egress systems following FB-6 (a) distorted elevator door on Floor 3; (b) stair detached from landing; (c) detached gypsum board around stair landing area. 


\section{Compartmentation Issues}

Compartment integrity can have a significant effect on fire growth, size, impact and spread, since ventilation openings serve both to supply oxygen to the fire and provide an avenue for hot gases to escape. Regarding fire growth, the rate of combustion is greatly affected by the availability and rate of airflow [16]. In addition, if forced ventilation or wind-driven fire conditions exist, fire growth and spread can be significantly affected [17], as movement of air through compartment openings can influence the shape, length and orientation of the flame, which can impact ignition of secondary materials inside and outside of the compartment (e.g., flame extension outside of a door or window opening) as well as influencing the direction of spread of smoke and hot gases. The location of ventilation openings along vertical compartment barriers is also important, as openings in the lower half of a compartment barrier (below the neutral plane) will tend to supply oxygen to the fire while openings in the upper half of a compartment barrier (above the neutral plane) will act as an escape route for the upward travelling, more buoyant smoke.

The major performance concern during and following earthquakes is that compartment barriers (walls, ceilings, glazing systems) and opening protectives (doors, dampers) can become damaged, thus contributing to the spread of fire and smoke. For some aspects, such as performance of door closure, visual indications of damage (e.g., door not able to close completely) and direct measurement of resulting ventilation openings (e.g., area of gap resulting from incomplete door closure) was possible. For other aspects, such as the total ventilation area created by cracks in barrier linings (e.g., gypsum wallboard and ceiling systems), direct measurement of ventilation openings was not feasible. However, an approach to measure the total area of ventilation openings was devised using a blower door fan system.

\section{Blower Door Fan Tests}

A blower door fan system was used to measure total leakage area of compartment boundaries. In this type of test, a fan blows air into or out of a building compartment, creating either a positive or negative pressure differential between the inside and the outside. As the pressure differential is created, air is forced through all holes and penetrations of the building enclosure. This approach is commonly used to measure leakage areas and locations in building compartments as part of energy performance assessments.

Compartment integrity tests using the blower door fan system were performed on the Northeast room area of Floor 3 following each seismic motion tests using an Infiltec E3 blower door fan. Testing was limited to the Area 1, the SBR separated by the partition wall, and Area 2, the entire SBR and LBR area combined as shown in Fig. 14a. The compartment space characteristics, such as the area and volume, were measured prior to testing. The leakage area measured after construction and prior to the first motion test served as the benchmark data to compare the degradation of the compartmentation caused by the ground motion tests.

To accurately measure the leakage area all of the window openings and ceiling vents were sealed. The door fan system was installed tightly against the door frame as shown in Fig. 14b. Pressurizing and depressurizing of the room was achieved by setting the fan to supply or extract air from the compartment configuring the equipment appropriately. The manometer was adjusted as needed to provide the fan flow and pressure values of the compartment. These values are provided by measuring the pressure differentials between the outside and inside pressures of the compartment under investigation. Several readings from the manometer were used for each test to determine the effective leakage area (ELA) at 4 Pascal [10].

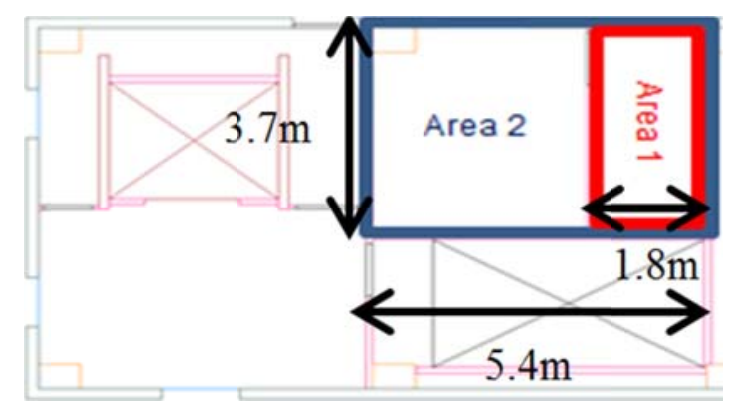

(a)

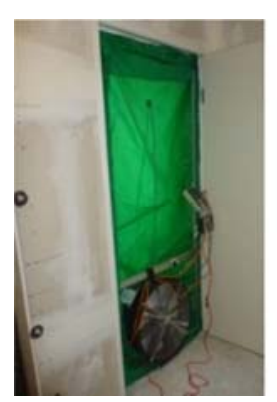

(b)

Fig. 14. Compartment integrity tests on Floor 3: (a) test areas 1 and 2 and (b) installation of blower door. 
Given the brief period of time between each motion test and subsequent building inspection, only one set of ELA data was able to be collected for each building damage state. Fig. 15 shows a plot of the change in ELA as a percentage, relative to the ELA measured before BI-1, versus the Floor 3 PIDR values of the building specimen from the motions. These ELA values are determined by performing a linear regression analysis on the five to seven readings of the fan flow rate and the pressure difference recorded during each test. This plot shows there was not much variance in the ELA for the smaller amplitude earthquake motions. Initially, the ELA of Area 1 was greater than the ELA of Area 2 up to FB-4, which was attributed to the leakage areas formed in the partition wall at the edges where the fire door frame was installed. A significant increase in the ELA for both testing areas is seen following the larger amplitude earthquake motion tests of FB-5 and FB-6. With more gaps created during the larger motion tests and taking into consideration the great disparity in size between the two compartments, the ELA of Area 2 surpassed the ELA of Area 1 following FB-4 [10].

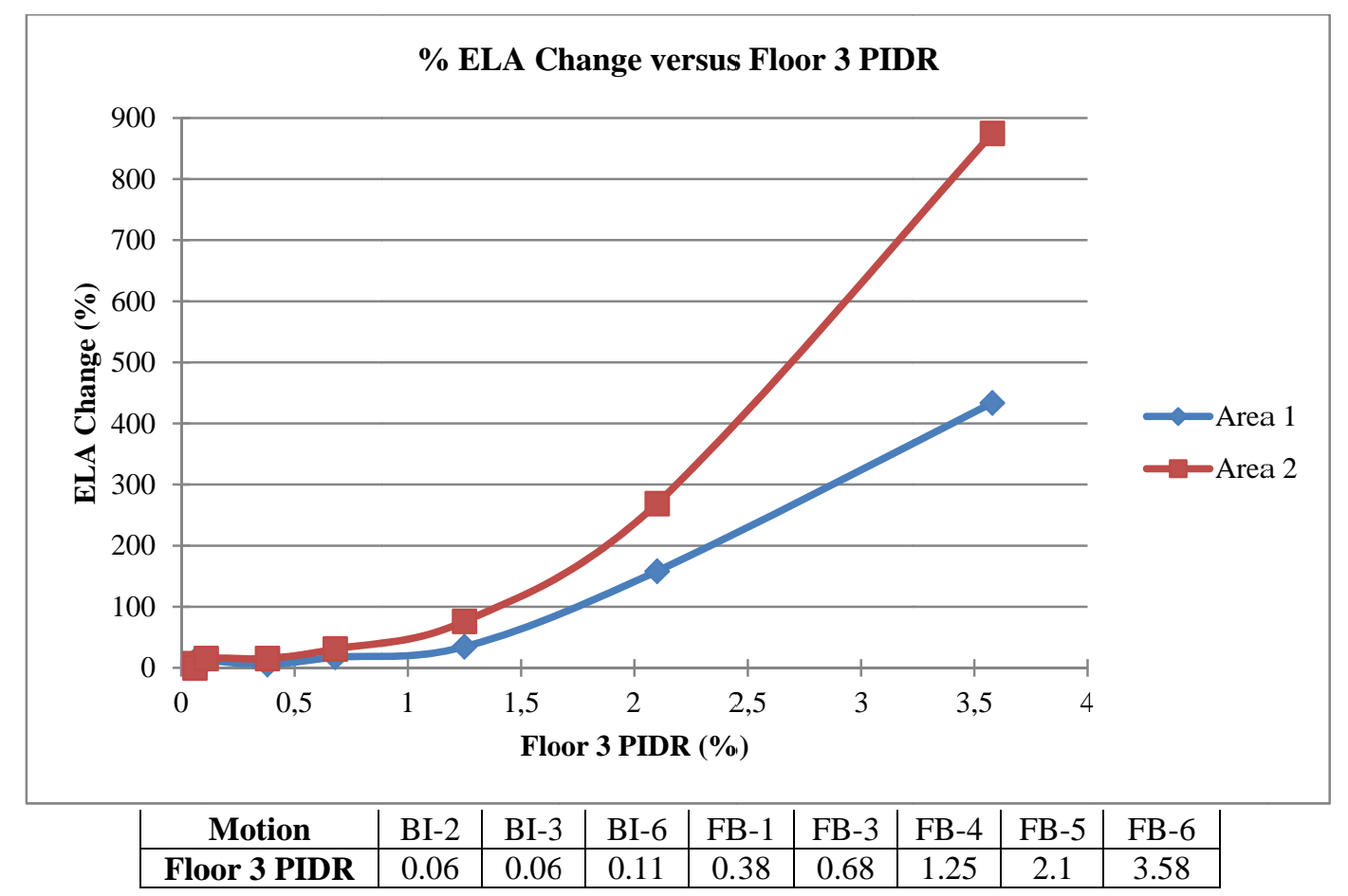

Fig. 15. Plot of \% ELA change relative to 'Before BI-1' versus PIDR of Floor 3

As a result of the large inter story drifts imposed during FB-5 and FB-6 [9], damage to compartment barriers became significant. The balloon framed façade system for Floors 1-3 developed large gaps in joint areas, particularly where the interior sides (gypsum board) met floor slabs, columns, ceiling systems and any perpendicular bracing walls. Examples of wall-ceiling system joints, façade connection to floor slab, and exterior façade separation are shown in Fig. 16a-c.

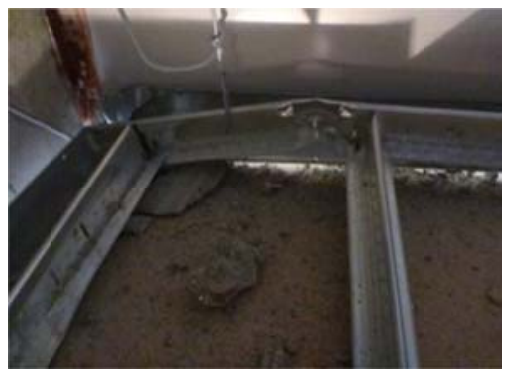

(a)

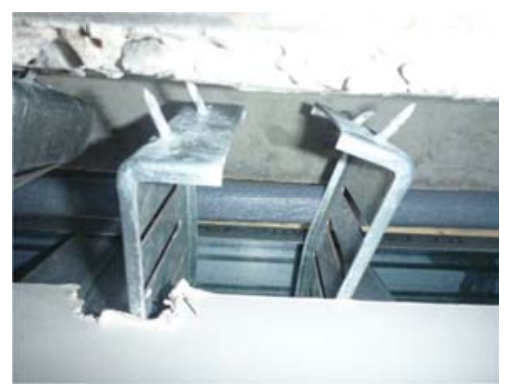

(b)

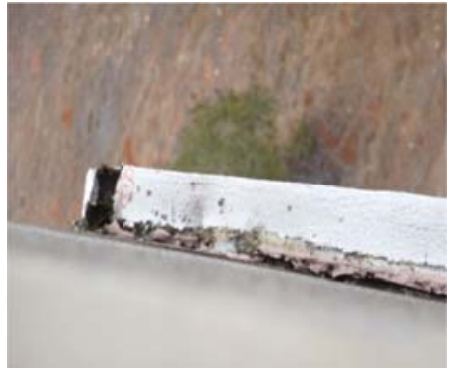

(c)

Fig. 16. Issues affecting compartment integrity (a) Gap formed at North balloon framing and ceiling joint of Floor 3; (b) detached balloon framing connection clips; (c) gaps developed at the EIFS façade. 
In addition to the outcomes of the blower door fan tests discussed above, other compartment barrier damage, which could potentially affect and degrade compartment barrier performance in real buildings, was observed on Floor 3 and other floors as well, including:

- All dynamic firestop systems remained largely intact during the motion tests, as did static firestop systems on joints which remained intact. However, during earthquake motions, some joints that would be static in normal building operation became dynamic and did not remain intact, and gaps of up to 25 $\mathrm{mm}$ were observed. An example is the joint areas where the interior side of the exterior wall met columns, floors and ceilings [10]. Damage to fire stopped joints can allow for smoke and fire spread.

- While the ceiling system on Floor 3 performed generally well, with the exception of gaps forming at wall joints (Fig. 16a), the ceiling system on Floor 1 showed progressive damage with increased earthquake motion intensity. Damage to ceiling systems can allow for smoke and fire spread.

- Two ICU breakout doors were installed in the stair landing area of Floor 4. These doors performed well throughout the motion tests, except during FB-5, when the ICU door from the landing to the Southwest room area became partially detached from the doorframe [10]. Damage to smoke doors can allow for smoke and fire spread.

- $\quad$ Fire dampers performed generally well. However, after FB-6, one damper out of three was not fully closed. This was due to the damper's blade rotation being prevented by a screw used for the damper installation which, once adjusted, allowed the damper to close completely [10]. Damage to dampers can allow for smoke and fire spread.

\section{Additional Observations [9]}

In addition to the damage detailed above, several other areas of concern and observations were noted, some of which were observed during fire testing, including:

- While glazing systems were not installed within the building specimen, fire tests were conducted with window openings closed and open. In tests where the windows were fully opened, flame extension was observed, smoke venting was observed, and the test fires were exposed to wind-driven conditions, which affected the combustion rate, smoke spread and flame angle direction during the fire tests. The concern here is that loss of windows could facilitate floor-to-floor fire spread and that wind-driven conditions resulting from loss of windows could result in much different fire conditions than the building fire protection systems are designed for or the fire department might expect.

- In various locations within the test specimen gypsum wallboard sections became detached during motion tests. The potential fire concern is loss of compartment integrity and spread of fire and smoke.

- Following the largest ground motions, significant spalling occurred on some of the concrete beamcolumn connections on the lower floors. This resulted in exposed steel reinforcing. The combination of connection damage and reinforcing bar exposure could impact the structural load-bearing capacity and fire performance of the connections and structural system. The potential fire performance concerns here are that the building could be at risk for localized structural failure and even collapse.

- The automatic fire sprinkler system performed well. In part this is attributed to the small floor areas, small pipe sizes, short pipe lengths, hanger spacing and seismic bracing needed to comply with code requirements. Testing of sprinkler system arrangements that reflect existing installations, which predated code requirements following the 1994 Northridge earthquake, for example, might yield different outcomes. Assessment of the performance of existing installations could yield interesting information.

\section{CONCLUSIONS}

The BNCS Project was undertaken to better understand building nonstructural system performance during earthquakes and post-earthquake fire hazards. Based on observations and data collected during these tests, a number of fire safety issues were identified. Most notably these include:

1. Earthquake motions can damage compartment barrier components by creating gaps at joint areas due to the movement of the components. In addition, earthquake motions can damage door frames and doors, 
leaving them unable to perform intended compartmentation functions. Such gaps and unintended openings reduce compartment integrity, resulting in unlimited flow of oxygen to a fire and unconstrained spread of smoke and flame, impacting both the control of the fire and the tenability of escape routes during the evacuation process.

2. Earthquake motion can render key portions of the means of egress unusable or can significantly hinder time to escape. During the earthquake motion tests, several means of egress components and alternate egress options were damaged, including the stairway and the elevator. In addition, the earthquake motions displaced contents, which could serve to hinder occupants from quickly and safely evacuating. The damage to the egress system and distribution of building contents can also impede emergency responder operations.

3. Important structural connections were damaged following the largest earthquake motions conducted in this test series, resulting in spalling of concrete and exposure of reinforcing steel. Such damage could degrade the fire resistance rating and load-bearing capacity of the structural member and/or system.

\section{ACKNOWLEDGMENTS}

This project was a collaboration of four academic institutions, University of California, San Diego, San Diego State University, Howard University and Worcester Polytechnic Institute, with support from the National Science Foundation (NSF), the Englekirk Advisory Board, the Charles Pankow Foundation, the California Seismic Safety Commission, more than 30 industry partners and two oversight committees. Their participation and support is greatly appreciated. Many students, faculty, technical staff, and other researchers, not on the authorship of this paper, contributed to the work leading to its findings and we are grateful for their contributions. A full listing of researchers and industry project sponsors that contributed to this project can be found on the project website: http://bncs.ucsd.edu/index.html. NSF funding was provided through the National Earthquake Engineering Simulation Research program under Dr. Joy Pauschke, program manager, through award CMMI-0936505. Support from this program is gratefully acknowledged. In addition, the technical support of NEES@UCSD staff, and consulting contributions from Robert Bachman, are greatly appreciated. Funding for the fire tests were provided by ARUP, Hilti, CSSC, The SFPE Educational \& Scientific Foundation, and WPI. The authors very much appreciate the above technical and financial support. Any summaries, opinions, findings, conclusions or recommendations expressed in this report are those of the authors and do not necessarily reflect project sponsors, institutions, agencies or organizations.

\section{REFERENCES}

[1] Park, H., Meacham, B.J. and Kim, J.K., "Fire Performance of Full-Scale Building Subjected to Earthquake Ground Motion: Fire Test Program and Outcomes,” IAFSS 2014, submitted in May, 2013.

[2] FEMA E-74 (2011). Reducing the Risks of Nonstructural Earthquake Damage - A Practical Guide. Applied Technology Council, Redwood City, CA.

[3] Kircher, C.A., "It Makes Dollars and Sense to Improve Nonstructural System Performance”, Proc. ATC 29-2 Seminar on Seismic Design, Performance, and Retrofit of Nonstructural Components in Critical Facilities, Newport Beach, CA October 23-24, 2003.

[4] Miranda, E., Mosqueda, G., Retamales, R., and Pekcan, G. (2012). Performance of Nonstructural Components during the 27 February 2010 Chile Earthquake, Earthquake Spectra 28: 453-471.

[5] Sekizawa, A., Ebihara, M. and Notake, H. (2003). "Development of Seismic-induced Fire Risk Assessment Method for a Building," Fire Safety Science - Proceedings of the Seventh International Symposium, International Association for Fire Safety Science, 309-320.

[6] Wilkinson, S., Grant, D., Williams, E., Paganoni, S., Fraser, S., Boon, D., Mason, A. and Free, M. (2013). "Observations and Implications of Damage From the Magnitude 6.3 Christchurch, New Zealand Earthquake of 22 February 2011,” Bull Earthquake Eng. 11: 107-140. DOI 10.1007/s10518-012-9384-5.

[7] Phan, L., and Taylor, A. (1996) State of the Art Report on Seismic Design Requirements for Nonstructural Building Components, NISTIR 5857, National Institute of Standards and Technology, Gaithersburg, MD. 
[8] Chen, M.C., Pantoli, E., Astroza, R., Ebrahimian, H., Mintz, S., Wang, X., Hutchinson, T., Conte, J., Restrepo, J., Meacham, B., Kim, J., and Park, H., 2013. BNCS Report \#1: Full-scale structural and nonstructural building system performance during earthquakes and post-earthquake fire specimen design, construction and test protocol. Structural Systems Research Project Report Series, SSRP 13/9. University of California San Diego, La Jolla, CA. (Forthcoming).

[9] Hutchinson, T., Restrepo J., Conte J. and Meacham, B.J. (2013). "Overview of the Building Nonstructural Components and Systems (BNCS) project,” Proceedings, ASCE Structures Congress, ASCE, Pittsburgh, PA, May 2013.

[10] Kim, J. K., Meacham, B.J. and Park, H. (2013). Full-Scale Structural and Nonstructural Building Systems Performance during Earthquakes and Post-Earthquake Fire: Fire Test Program and Preliminary Outcomes Worcester Polytechnic Institute, Worcester, MA.

[11] Pantoli, E., Chen, M.C., Astroza, R., Ebrahimian, H., Mintz, S., Wang, X., Hutchinson, T., Conte, J., Restrepo, J., Meacham, B., Kim, J., and Park, H., (2013). BNCS Report \#2: Full-scale structural and nonstructural building system performance during earthquakes and post-earthquake fire - test results. Structural Systems Research Project Report Series, SSRP 13/10. University of California San Diego, La Jolla, CA. (Forthcoming).

[12] Wang, X., Ebrahimian, H., Astroza, R., Conte, J., Restrepo, J. and Hutchinson, T. (2013). "Shake table testing of a full-scale five-story building: pre-test simulation of the test building and development of a nonstructural components and systems design criteria,” Proceedings, ASCE Structures Congress, ASCE, Pittsburgh, PA, May 2013.

[13] Pantoli, E., Chen, M., Wang, X., Hutchinson, T., Meacham, B. and Park, H. (2013). "Shake table testing of a full-scale five-story building: seismic performance of major nonstructural components: egress systems, facades,” Proceedings, ASCE Structures Congress, ASCE, Pittsburgh, PA, May 2013.

[14] American Society of Civil Engineers and Structural Engineering Institute, Minimum Design Loads for Buildings and Other Structures, Including Supplement NO. 1 (ASCE 7-05), 2005.

[15] Hokugo, A., Kaneko, T., Sekizawa, A., Kakegawa, S., and Notake H. (2011). A Study On Evacuation Simulation After Earthquake in Consumer Facilities, Pedestrian and Evacuation Dynamics 793-797.

[16] Quintiere, J.G., (2002). Fire Behavior in Building Compartments, Proceedings of the Combustion Institute, 29: 181-193.

[17] Madrzykowski, D. and Kerber, S. (2009). Fire Fighting Tactics Under Wind Driven Conditions: Laboratory Experiments, NIST Technical Note 1618, National Institute of Standards and Technology, Gaithersburg, MD. 